COMMENT

DOI: $10.1057 /$ s41599-018-0063-2

\title{
What has economics got to do with it? The impact of socioeconomic factors on mental health and the case for collective action
}

\author{
Anna Macintyre ${ }^{1}$, Daniel Ferris² ${ }^{2}$ Briana Gonçalves $^{3} \&$ Neil Quinn ${ }^{1}$
}

\begin{abstract}
A clear link exists between social and economic inequality and poor mental health. There is a social gradient in mental health, and higher levels of income inequality are linked to higher prevalence of mental illness. Despite this, in the late 20th and early 21st century, psychiatric and psychological perspectives have dominated mental health research and policy, obscuring root socioeconomic contributors. Drawing on contemporary research on the social determinants of mental health, with particular reference to Europe and the U.S., this paper argues that a sharper focus on socioeconomic factors is required in research and policy to address inequalities in mental health. Current attempts to move this direction include: evaluation of the impact of economic policies on mental health, community-based partnerships, increased professional awareness and advocacy on socioeconomic factors. This necessitates greater understanding of the barriers to such actions. This paper argues that advancing 'upstream' approaches to population mental health requires an interdisciplinary research vision that supports greater understanding of the role of socioeconomic factors. It also demands collective cross-sectoral action through changes in social and economic policy, as well as economic frameworks that move beyond an exclusive focus on economic growth to embrace collective and societal wellbeing.
\end{abstract}

\footnotetext{
${ }^{1}$ Centre for Health Policy, University of Strathclyde, Glasgow, UK. ${ }^{2}$ Brown School of Social Work at Washington University; Envolve Center for Health Behavior Change, St. Louis, MO, USA. ${ }^{3}$ McSilver Institute for Poverty Policy and Research at New York University Silver School of Social Work, New York, NY, USA. Correspondence and requests for materials should be addressed to A.M. (email: anna.macintyre@strath.ac.uk)
} 


\section{The importance of socioeconomic factors for mental health}

'Economics is the mother tongue of public policy, the language of public life, and the mindset that shapes society' (Raworth, 2017, p. 6)

Growing evidence connects economic inequality and poor mental health (Friedli, 2009; Pickett and Wilkinson, 2010; Platt et al., 2017). Experience of socioeconomic disadvantage, including unemployment, low income, poverty, debt and poor housing, is consistently associated with poorer mental health (Silva et al., 2016; Elliott, 2016; Platt et al., 2017; Friedli, 2009, Rogers and Pilgrim, 2010). Mental health problems are particularly prominent amongst marginalised groups experiencing social exclusion, discrimination and trauma, leading to compound vulnerability (Rafferty et al., 2015). Greater inequality within societies is associated with greater prevalence of mental illness (Wilkinson and Pickett, 2009; Pickett and Wilkinson, 2010), and economic recessions have had devastating impacts on population mental health (Platt et al., 2017; Wahlbeck and McDaid, 2012). At a global level, mental health and substance use disorders account for between one fifth and almost one third of Years Lived with Disability (Whiteford et al., 2013; Vigo et al., 2016). At the same time there is increasing interest in how to promote positive mental health at a societal level (Friedli, 2009; Rogers and Pilgrim, 2010; Hanlon and Carlisle, 2013).

However, the dominance of medical, psychiatric and psychological perspectives on mental health from the 1970s onwards has distracted from socioeconomic factors (Smith, 2016b; Shim et al., 2014). Drawing on contemporary research on the social determinants of mental health, with particular reference to Europe and the U.S., this paper argues that a sharper focus on socioeconomic factors is required in research and policy to address inequalities in mental health.

\section{Contemporary research on socioeconomic determinants of mental health}

'Today, in the wake of the global economic slowdown, rising rates of mental illness and disaffection with psychopharmacology, the idea that there are social determinants of mental health is taking root once more'. (Smith, 2016b, p. 9)

There is growing interest across disciplines in understanding and addressing the social determinants of mental health (Friedli, 2009; Fisher and Baum, 2010; Bowen and Walton, 2015; Kinderman, 2016; Compton and Shim, 2015; Smith, 2016b; Silva et al., 2016). This sits alongside increased attention to public mental health, and the promotion of positive societal well-being (Wahlbeck, 2015; Rogers and Pilgrim, 2010; Hanlon and Carlisle, 2013). The role of psychosocial factors and chronic stress has also been emphasised in understanding health inequalities (Fisher and Baum, 2010; Wilkinson and Pickett, 2017). Furthermore, stigma (a ubiquitous component of mental health difficulties), has been recognised as a fundamental cause of health inequalities (Hatzenbuehler et al., 2013).

However, within the broad literature on the social determinants of mental health, to what extent are socio-economic factors considered? There is consistent evidence supporting the link between socioeconomic inequality in terms of income, employment, and neighbourhood environments and poorer mental health outcomes (Silva et al., 2016). At an ecological level, a significant relationship has been shown between higher income inequality (as measured by the Gini coefficient) and higher incidence rates of schizophrenia (Burns et al., 2014). In addition, the connection between experience of socioeconomic disadvantage and increased risk of suicidal behaviour has also been established (Platt et al., 2017). Furthermore, the association between educational inequalities and mental health outcomes may be attenuated by controlling for employment status, indicating the importance of employment for mental health (Katikireddi et al., 2016). At a community level, low socioeconomic status may lead to greater concerns about neighbourhood safety, and decrease the amount of physical activity in the community, with consequent impacts on mental health (Meyer et al., 2014). A focus on socioeconomic factors may also link with ideas of social capital or community efficacy, measures of trust and commitment by residents to a neighbourhood (Platt et al., 2017), which have been linked to rates of depression, suicide, and internalising behaviours (Schmidt et al., 2014).

Many argue for a renewed focus on social justice, advocating for the significance of socioeconomic factors for mental health (Friedli, 2009; Rogers and Pilgrim, 2010). The impact of material and economic conditions and consumerism on population wellbeing is also recognised (Rogers and Pilgrim, 2010; Friedli, 2009). From a U.S. perspective, Jones et al. (2009) offer a theoretical framework to identify the social determinants of inequity shaped by systems of power and the distribution of resources, including an economic system that creates class structures and dimensions of opportunity (Jones et al., 2009). In addition, disparities in education and income play a major role in understanding racial difference in health and mental health (Williams et al., 1997). Krieger et al. (1997) argue that social class, at the household and community level, predicts inequalities in health (Krieger et al., 1997), and the role of economic inequality, poverty, and deprivation is implicated in poor mental health in the United States (Compton and Shim, 2015; Manseau, 2015).

Despite this, in comparison with biomedical, neuropsychiatric and psychological literature, the social determinants of mental health are strikingly understudied (Shim et al., 2014). In Europe, research on the prevention of poor mental health has received a comparatively low level of investment (Wykes et al., 2015). In the United States, funding of prevention constitutes a notoriously small percentage of overall healthcare expenditures (Miller et al., 2012). Yet the economic cost of treatment and lost productivity related to mental health and substance use disorder is well documented. While the National Institute for Mental Health named prevention as a core objective in its strategic plan for research (National Institute for Mental Health, 2015), there is not a clear picture of the scope and scale of investment in mental health prevention across government and philanthropy. It is likely there has been even less investment in research on the social determinants of mental health, and socioeconomic factors in particular. Thus, there is a need for greater research capacity (Wahlbeck and McDaid, 2012).

\section{Moving from evidence to action: policy, communities and practice}

'levels of mental distress among communities need to be understood less in terms of individual pathology and more as a response to relative deprivation and social injustice' (Friedli, 2009, p.III)

However, it is not only further evidence on the link between economic inequality and mental health that is required, but also action to address it (Smith, 2016b). This may require a shift from addressing individuals' psychological states to a focus on social justice and broader economic conditions. Current attempts to move this direction include action in policy, communities and service provision. 
In policy, this agenda was advanced by a World Health Organisation report in 2014, which highlighted the social determinants of mental health at an international level (World Health Organization, 2014). In Europe, the Joint Action on Mental Health has championed a focus on 'Mental Health in All Policies', which promotes action in non-health policy areas including employment and welfare (EU Directorate General for Health and Food Safety, 2015). Evidence is beginning to accumulate on relevant policy actions, including labour market regulation (Katikireddi et al., 2016) and part-time sickness absence (EU Directorate General for Health and Food Safety, 2015), investment in social protection (Niedzwiedz et al., 2016), and protective employment policies (Platt et al., 2017). In the United States, better population health outcomes have also been found in states with more progressive policies such as minimum wage and corporate tax rates (Rigby and Hatch, 2016). It has also been raised that a Universal Basic Income might positively impact on population mental health (Smith, 2016b). Whilst there is evidence for interventions which can lessen the impact of poverty and inequality on mental health, including interventions aimed at the individual or family level (e.g., parenting interventions), evidence is more limited on community interventions or on cross-sectoral action on policies (Wahlbeck et al., 2017).

At a community level, the expansion of the Community Schools model in the U.S., which provides children in socioeconomically disadvantaged areas, with access to health services (medical, dental, vision and counselling services), brings more holistic attention to the education and healthy development of children (Oakes and Daniel, 2017). Education policies that recognise structural inequalities show promise to close the economic and achievement gap. Additionally, New York City has launched Thrive NYC, a comprehensive city-based mental health plan to reduce stigma, intervene early, and improve access to services (NYC Thrive, 2016). Encouraging partnership and reducing silos, a major component of the initiative, has linked community based organisations serving the most socially and economically disadvantaged populations with mental health providers to increase access to mental health and substance use services (Chapman et al., 2017). Furthermore, efforts at a community level which promote social capital are promoted as a buffer against the impact of socioeconomic factors (Wahlbeck and McDaid, 2012).

At the level of service provision, there are moves to increase professional awareness and advocacy on the social determinants of mental health (Compton and Shim, 2015, Shim et al., 2014). This may include a focus on social justice and socioeconomic factors in therapeutic work. Kinderman argues 'practical help to resolve real-world issues such as debt, employment issues, housing problems and domestic violence' may be important roles for clinicians (Kinderman, 2016, p. 4). Shim et al. (2014) also suggest that mental health professionals have an advocacy role to influence public policies that impact on mental health (Shim et al., 2014). Bowen and Walton argue that there is a role for social workers in addressing racial and ethnic disparities in mental health (Bowen and Walton, 2015). One relevant example from the U.K. is the work of Psychologists Against Austerity, who have campaigned on the mental health impact of welfare policies (McGrath et al., 2016).

\section{Trying to focus 'upstream': barriers to action on socioeconomic factors}

'We are failing on health equity because we are failing on equity' (Braveman, 2012, p. 515)
A distinction is often made between 'upstream societal influences' (which can include living and working conditions and wider societal structures) and 'downstream risk factors' (which include behaviours such as smoking or drinking as well as biological risk factors) (Graham, 2009, p. 472). To effectively take action on socioeconomic factors and mental health, there is a need for awareness of what might pull research and policy 'downstream' (Douglas, 2016; Graham, 2009). These barriers might include the dominance of the current economic paradigm, a focus on psychological or community resilience, ignoring factors like structural racism, or the challenges of mental health care provision.

In health inequalities research it is argued that an exclusive focus on health may over-medicalise the issue, veiling the fundamental problem of social inequality (Lynch, 2017; Douglas, 2016). It is stated that efforts should include awareness of the socioeconomic and political contexts which generate health inequalities, particularly the influence of neoliberalism (Smith et al., 2016a; Collins et al., 2016) Such arguments are equally salient to mental health. However, focusing 'upstream' presents challenges given that the dominant neoliberal paradigm 'actively embraces inequality' (Collins et al., 2016, p. 129). This may point to confronting the current inequitable economic paradigm and considering alternatives to economic growth that incorporate broader social and environmental concerns (Fioramonti, 2016; Raworth, 2017). A sharper focus on fundamental inequalities, and the economic system which underpins them, may be critical to addressing the 'upstream' influences on mental health.

It has also been argued that it may be problematic to focus on psychological or community assets and strengths, and social capital, as this may mask a focus on socioeconomic factors, which are fundamental causes of distress (Friedli, 2016; Rogers and Pilgrim, 2010; Knifton, 2015). Indeed, Friedli argues: 'Choosing psycho-analysis over economic analysis has serious consequences for how public health explains and responds to issues of social justice' (Friedli, 2016, p. 216, original emphasis). This argument may be particularly relevant for mental health, where psychological conceptualisations may predominate. Within a neoliberal policy framework, there is the danger of endorsing individualistic conceptualisations of complex social and economic problems, where the predominant biomedical model has often resulted in a systematic neglect of the impact of social and structural barriers experienced by people with poor mental health (Bayetti et al., 2016; Friedli, 2016). Thus, whilst the relevance of psychosocial factors is recognised, it is important to increase the salience of social and economic inequalities which generate inequalities in mental health at a population level.

Furthermore, it is critical to consider race and ethnicity (Lynch and Perera, 2017). While racism has been identified as a social determinant of health, there is a significant lack of research or policy to address it (Bailey et al., 2017; Rafferty et al., 2015). Advancing policies to tackle structural racism may have significant implications for population mental health. Despite having distinct healthcare systems and ideologies on healthcare access, both the U.S. and U.K. have significant health inequalities by race and ethnicity (Bailey et al., 2017; Department of Health, 2009). Research on mental health and racial discrimination has largely considered interpersonal discrimination, not structural racism and the link to inequalities (Bailey et al., 2017). While increased funding and resources for mental health services and prevention is needed, greater attention must be given to addressing structural racism that leads to inequalities in education, employment, and mental health.

Finally, the need to ensure adequate mental health care provision is a pressing concern in both Europe and the U.S. Indeed, many OECD countries face ongoing challenges regarding 
adequate levels of resourcing for mental health services (Wahlbeck and McDaid, 2012). Current healthcare policy debates in the U.S. threaten progress in increasing the number of insured individuals as well as what services they can receive. Current debate, focused on insurance access and eligibility, is troublingly void of a focus on prevention or addressing social determinants and structural racism. In fact, while mental health care access improved following implementation of the Affordable Care Act, there was no progress in reducing racial and ethnic disparities (Creedon and Le Cook, 2016). While advocates and researchers are pulled toward policy and legislative fights over healthcare provision, larger macro issues impacting health and mental health, i.e. social determinants, are lost. Negotiating space for dialogue on the importance of prevention, alongside service provision, will be crucial.

\section{Conclusions: taking collective action}

Smith (2016b) argues that a focus on socioeconomic factors and mental health is not new, but had previously gained ground in the early 20th century (Smith, 2016b). As a renewed interest emerges in the current context, there are increasing calls for collective actions (Kinderman, 2016) and inter-disciplinary and intersectoral approaches, which re-invigorate a focus on fundamental socioeconomic inequalities and social justice (Friedli, 2009; Braveman, 2012).

Encouragingly, the growing body of research on socioeconomic factors and social determinants of health is narrowing in on mental health. Diagnosing problems, however, is not enough. Evidence on policy actions and a collective appreciation of issues that prevent upstream approaches is also needed: structural barriers including racism and discrimination, the medicalising of population mental health, access and quality of services, and ultimately the economic system itself.

To advance upstream approaches will require an interdisciplinary research vision which extends beyond biomedical, neuropsychiatric and psychological models of mental health, and which supports greater understanding of the role of socioeconomic factors and economics. It will necessitate bold crosssectoral policy action including changes to wider social and economic policies such as social protection, taxation, employment and housing policy, as well as health policy. Given the ubiquity and influence of economics, this agenda should be supported by the advancement of paradigms that move beyond an exclusive focus on economic growth (Raworth, 2017; Fioramonti, 2016), and which appreciate the importance of collective and societal wellbeing (Knifton, 2015).

Population mental health is intimately connected to societal economic conditions. The (poor) mental health of modern societies offers a stark indication of the consequences of not taking action: 'economic growth at the cost of social recession' (Friedli, 2009, p. IV). Socioeconomic inequality may be 'the enemy between us' (Wilkinson and Pickett, 2017, p. 11), increasing status competition, undermining the quality of social relations, increasing stress and impacting on health, mental health, and wellbeing. In response to this, there is a need to build an economic system that tackles these inequalities in mental health.

Received: 1 November 2017 Accepted: 19 December 2017 Published online: 30 January 2018

\section{References}

Bailey ZD, Krieger N, Agenor M, Graves J et al. (2017) Structural racism and health inequities in the USA: evidence and interventions. Lancet 389:1453-1463
Bayetti C, Jadhavb S, Jainc S (2016) The Re-covering self: a critique of the recoverybased approach in India's mental health care. Disabil Glob South 3:889-909

Bowen EA, Walton QL (2015) Disparities and the social determinants of mental health and addictions: opportunities for a multifaceted social work response. Health Soc Work 40:E59-E65

Braveman P (2012) We are failing on health equity because we are failing on equity. Aust N Z J Public Health 36:515-515

Burns JK, Tomita A, Kapadia AS (2014) Income inequality and schizophrenia: Increased schizophrenia incidence in countries with high levels of income inequality. Int J Social Psychiatr 60:185-196

Chapman E, Chung H, Pincus HA (2017) Using a continuum-based framework for behavioral health integration into primary care in New York state. Psychiatr Serv 68:756-758

Collins C, McCartney G, Garnham L (2016) Neoliberalism and health inequalities. In: Smith KE, Hill S, Bambra C (eds) Health inequalities: critical perspectives. Oxford University Press, Oxford

Compton MT, Shim RS (2015) Social determinants of mental health. American Psychiatric Publishing, Washington

Creedon TB, Le Cook B (2016) Access to mental health care increased but not for substance use, while disparities remain. Health Aff 35:1017-1021

Department of Health (2009) Tackling health inequalities: 10 years on-a review of developments in tackling health inequalities in England over the last 10 years. Department of Health, London

Douglas M (2016) Beyond 'health': why don't we tackle the cause of health inequalities? In: Smith KE, Hill S, Bambra C (eds) Health inequalities: critical perspectives. Oxford University Press, Oxford

EU Directorate General for Health and Food Safety (2015) Joint action on mental health and well-being. Mental Health in all Policies-situation analysis and recommendations for action. http://www.mentalhealthandwellbeing.eu/ assets/docs/publications/MHiAP\%20Final.pdf. Accessed 20 Jul 2017

Elliott I (2016) Poverty and mental health: A review to inform the Joseph Rowntree Foundation's Anti-Poverty Strategy. Mental Health Foundation, London

Fioramonti L (2016) A post-GDP world? Rethinking international politics in the 21 (st) century. Glob Policy 7:15-24

Fisher M, Baum F (2010) The social determinants of mental health: implications for research and health promotion. Aust NZ J Psychiatr 44:1057-1063

Friedli L (2009) Mental health, resilience and inequalities. World Health Organization, Copenhagen

Friedli L (2016) The politics of tackling inequalities: The rise of psychological fundamentalism in public health and welfare reform. In: Smith KE, Hill S, Bambra C (eds) Health inequalities: critical perspectives. Oxford University Press, Oxford

Graham H (2009) Health inequalities, social determinants and public health policy. Policy \& Polit 37:463-479

Hanlon P, Carlisle S (2013) Positive mental health and wellbeing: connecting individual, social and global levels of wellbeing. In: Knifton L, Quinn N (eds) Public mental health: global perspectives. Open University Press, Maidenhead

Hatzenbuehler ML, Phelan JC, Link BG (2013) Stigma as a fundamental cause of population health inequalities. Am J Public Health 103:813-821

Jones CP, J C, Perry GS, Barclay G, Jones CA (2009) Addressing the social determinants of children's health: a cliff analogy. J Health Care Poor Under 20:1-12

Katikireddi SV, Niedzwiedz CL, Popham F (2016) Employment status and income as potential mediators of educational inequalities in population mental health. Eur J Public Health 26:814-816

Kinderman P (2016) Knots and black holes: why we are all prone to madness and what we can do about it. Palgrave Commun 2:16074. https://doi.org/10.1057/ palcomms.2016.74

Knifton L (2015) Collective wellbeing in public mental health. Perspect Public Health 135:24-26

Krieger N, Williams DR, Moss NE (1997) Measuring social class in US public health research: concepts, methodologies, and guidelines. Annu Rev Public Health 18:341-378

Lynch J (2017) Reframing inequality? The health inequalities turn as a dangerous frame shift J Public Health 39:1-8

Lynch JF, Perera IM (2017) Framing Health Equity: US health disparities in comparative perspective J Health Polit Policy Law 42:803-839

Manseau MW (2015) Economic inequality, poverty and neighbourhood deprivation. In: Compton MT, Shim RS (eds) The social determinants of mental health. American Psychiatric Publishing, Washington

McGrath L, Griffin V, Mundy E (2016) The Psychological Impact of Austerity. A briefing paper. Educational Psychology Research and Practice 2:46-57

Meyer OL, Castro-Schilo L, Aguilar-Gaxiola S (2014) Determinants of mental health and self-rated health: a model of socioeconomic status, neighborhood safety, and physical activity. Am J Public Health 104:1734-1741

Miller G, Roehrig C, Hughes-Cromwick P, Turner A (2012) What is currently spent on prevention as compared to treatment?. In: Faust H, M P (eds) 
Prevention vs. treatment: what's the right balance?. Oxford University Press, New York

National Institute of Mental Health (NIOM) (2015) Strategic objective 3. https:// www.nimh.nih.gov/about/strategic-planning-reports/strategic-objective-3. shtml

Niedzwiedz CL, Mitchell RJ, Shortt NK, Pearce JR (2016) Social protection spending and inequalities in depressive symptoms across Europe. Soc Psychiatry Psychiatr Epidemiol 51:1005-1014

NYC Thrive (2016) Thrive NYC. A roadmap for mental health for all. https:// thrivenyc.cityofnewyork.us/wp-content/uploads/2017/02/ThriveNYC.pdf

Oakes J, Maier A, Daniel J (2017) Community schools: an evidence-based strategy for equitable school improvement. National Education Policy Center, Boulder, $\mathrm{CO}$

Pickett KE, Wilkinson RG (2010) Inequality: an underacknowledged source of mental illness and distress. Br J Psychiatr 197:426-428

Platt S, Stace S, Morrissey J (eds) (2017) Dying From Inequality: Socioeconomic Distadvantage and Suicidal Behaviour. Samaritans, London

Rafferty JA, Abelson JM, Bryant K, Jackson JS (2015) Discrimination. In: Compton MT, Shim RS (ed) The Social Determinants of Mental Health. American Psychiatric Publishing, Washington

Raworth K (2017) Doughnut economics. Seven ways to think like a 21st-century economist. Random House Business Books, London

Rigby E, Hatch ME (2016) Incorporating economic policy into a 'health-in-allpolicies' agenda. Health Aff 35:2044-2052

Rogers A, Pilgrim D (2010) A sociology of mental health and illness. Open University Press, Maidenhead

Schmidt NM, Tchetgen Tchetgen EJ, Ehntholt A, Almeida J, Nguyen QC, Molnar BE, Azrael D, Osypuk TL (2014) Does neighborhood collective efficacy for families change over time? The Boston Neighborhood Survey. J Commun Psychol 42:61-79

Shim R, Koplan C, Langheim FJP, Manseau MW et al. (2014) The social determinants of mental health: an overview and call to action. Psychiatr Ann 44:22-26

Silva M, Loureiro A, Cardoso G (2016) Social determinants of mental health: a review of the evidence. Eur J Psychiatry 30:259-292

Smith KE, Hill S, Bambra C (eds) (2016a) Conclusion-where next for advocates, researchers, and policymakers trying to tackle health inequalities? In: Health inequalities. Critical perspectives. Oxford University Press, Oxford

Smith M (2016b) A fine balance: individualism, society and the prevention of mental illness in the United States, 1945-1968. Palgrave Commun 2. https:// doi.org/10.1057/palcomms.2016.24

Vigo D, Thornicroft G, Atun R (2016) Estimating the true global burden of mental illness. Lancet Psychiatr 3:171-178

Wahlbeck K (2015) Public mental health: the time is ripe for translation of evidence into practice. World Psychiatr 14:36-42

Wahlbeck K, Cresswell-Smith J, Haaramo P, Parkkonen J (2017) Interventions to mitigate the effects of poverty and inequality on mental health. Soc Psychiatr Psychiatr Epidemiol 52:505-514

Wahlbeck K, McDaid D (2012) Actions to alleviate the mental health impact of the economic crisis. World Psychiatr 11:139-145

Whiteford HA, Degenhardt L, Rehm J, Baxter AJ et al. (2013) Global burden of disease attributable to mental and substance use disorders: findings from the Global Burden of Disease Study 2010. Lancet 382:1575-1586

Wilkinson R, Pickett K (2009) The Spirit level. Why equality is better for everyone Penguin Books, London

Wilkinson RG, Pickett KE (2017) The enemy between us: The psychological and social costs of inequality. Eur J Soc Psychol 47:11-24

Williams DR, Y Y, Jackson JS, Anderson NB (1997) Racial differences in physical and mental health: Socio-economic status, stress and discrimination. J Health Psychol 2:335-351

World Health Organization and Calouste Gulbenkian Foundation (WHOCG) (2014) Social determinants of mental health. World Health Organization, Geneva

Wykes T, Haro JM, Belli SR, Obradors-Tarrago C et al. (2015) Mental health research priorities for Europe. Lancet Psychiatr 2:1036-1042

\section{Acknowledgements}

The collaboration for this paper was made possible by a European Union funded Horizon 2020 RISE project 'Citizenship, Recovery and Inclusive Society Partnership' (www. crisppartnership.eu). This project has received funding from the European Union's Horizon 2020 research and innovation programme under the Marie Sklodowska-Curie grant agreement, No 690954. The views in this publication are solely the responsibility of the authors. The Commission is not responsible for any use that may be made of the information it contains.

\section{Additional information}

Competing interests: The authors declare no competing financial interests.

Reprints and permission information is available online at http://www.nature.com/ reprints

Publisher's note: Springer Nature remains neutral with regard to jurisdictional claims in published maps and institutional affiliations.

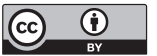

Open Access This article is licensed under a Creative Commons Attribution 4.0 International License, which permits use, sharing, adaptation, distribution and reproduction in any medium or format, as long as you give appropriate credit to the original author(s) and the source, provide a link to the Creative Commons license, and indicate if changes were made. The images or other third party material in this article are included in the article's Creative Commons license, unless indicated otherwise in a credit line to the material. If material is not included in the article's Creative Commons license and your intended use is not permitted by statutory regulation or exceeds the permitted use, you will need to obtain permission directly from the copyright holder. To view a copy of this license, visit http://creativecommons.org/ licenses/by/4.0/

(c) The Author(s) 2018 